\title{
Concurrent delivery of soluble and immobilized proteins to recruit and differentiate neural stem cells
}

\author{
Trevor R. Ham, ${ }^{\dagger}$ Dakotah G. Cox ${ }^{\ddagger}$ and Nic D. Leipzig*, ${ }^{*, \dagger}$ \\ $\dagger$ Department of Biomedical Engineering, Auburn Science and Engineering Center 275, \\ West Tower, The University of Akron, Akron, OH 44325, United States \\ $\ddagger$ Department of Chemical and Biomolecular Engineering, Whitby 211, The University of \\ Akron, Akron, OH 44325, United States \\ E-mail: nl21@uakron.edu
}

Supporting Information Available 


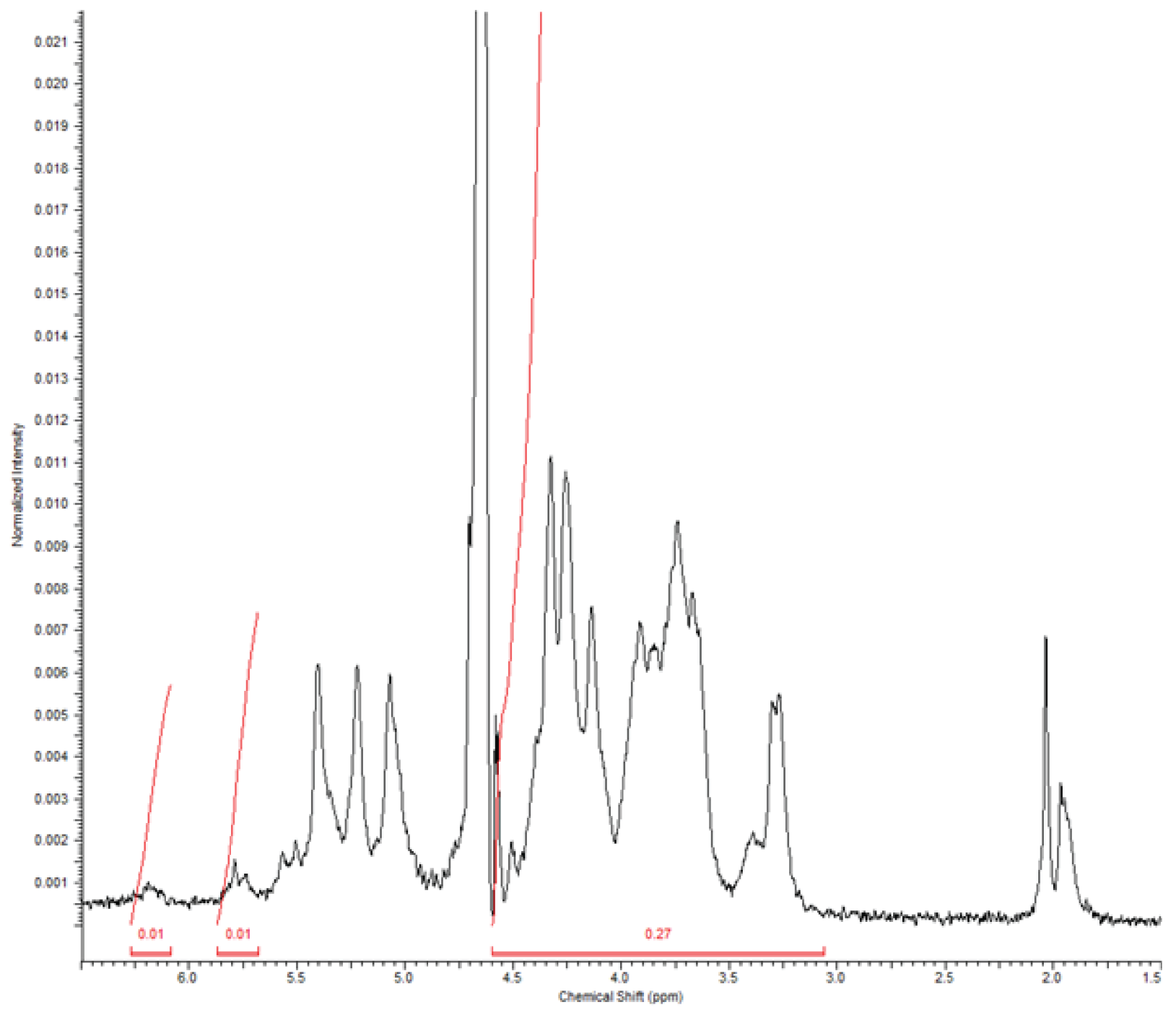

Figure S1: ${ }^{1} \mathrm{H}$ NMR of methacrylated heparin in $\mathrm{D}_{2} \mathrm{O}$. A spectrum for MAC can be found in (21) 


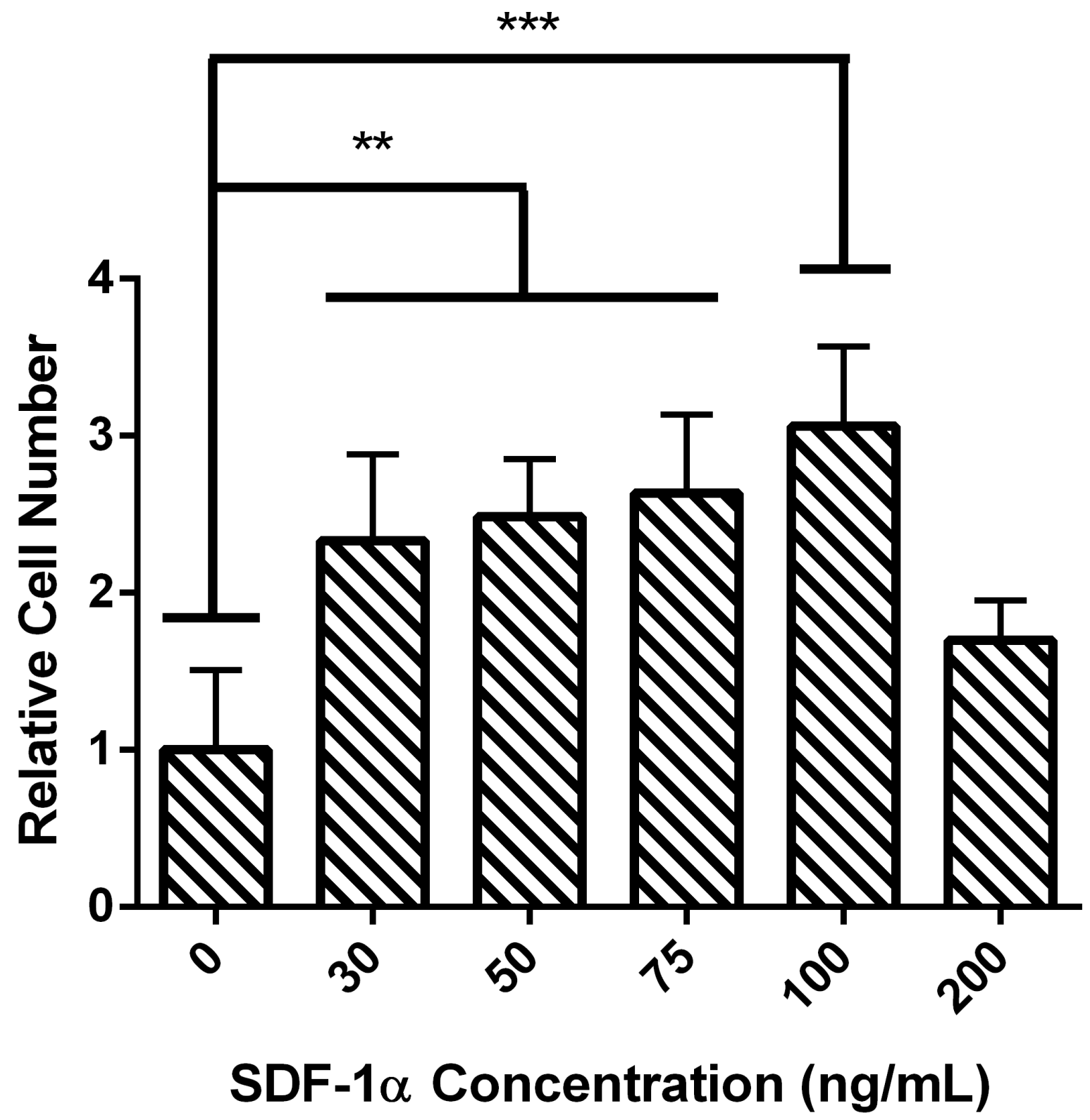

Figure S2: Verification of the bioactivity of soluble SDF- $1 \alpha$ on our NSC population. ${ }^{* *}$ or $* * *$ indicates $\mathrm{p}<0.001$ or 0.0001 , respectively. Mean $\pm \mathrm{SD}, \mathrm{n}=4$. Significance determined by one-way ANOVA with Tukey's post-hoc. 


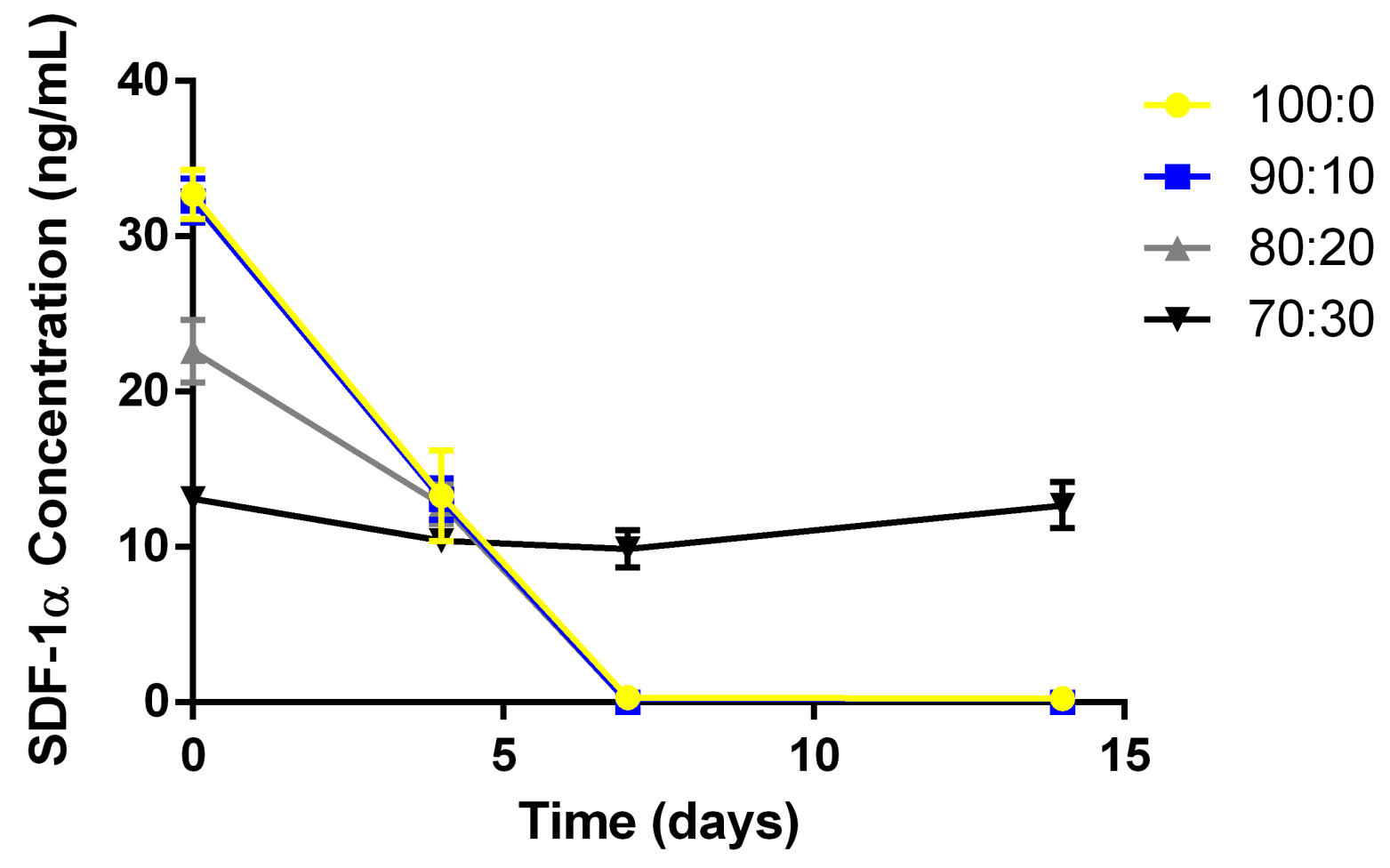

Figure S3: The concentration of SDF- $1 \alpha$ within the wells during the NSC recruitment experiment shown in Figure 4. This is the concentration that the NSCs experienced within each well during the migration period, after changing the media. Mean $\pm \mathrm{SD}, \mathrm{n}=4$ 


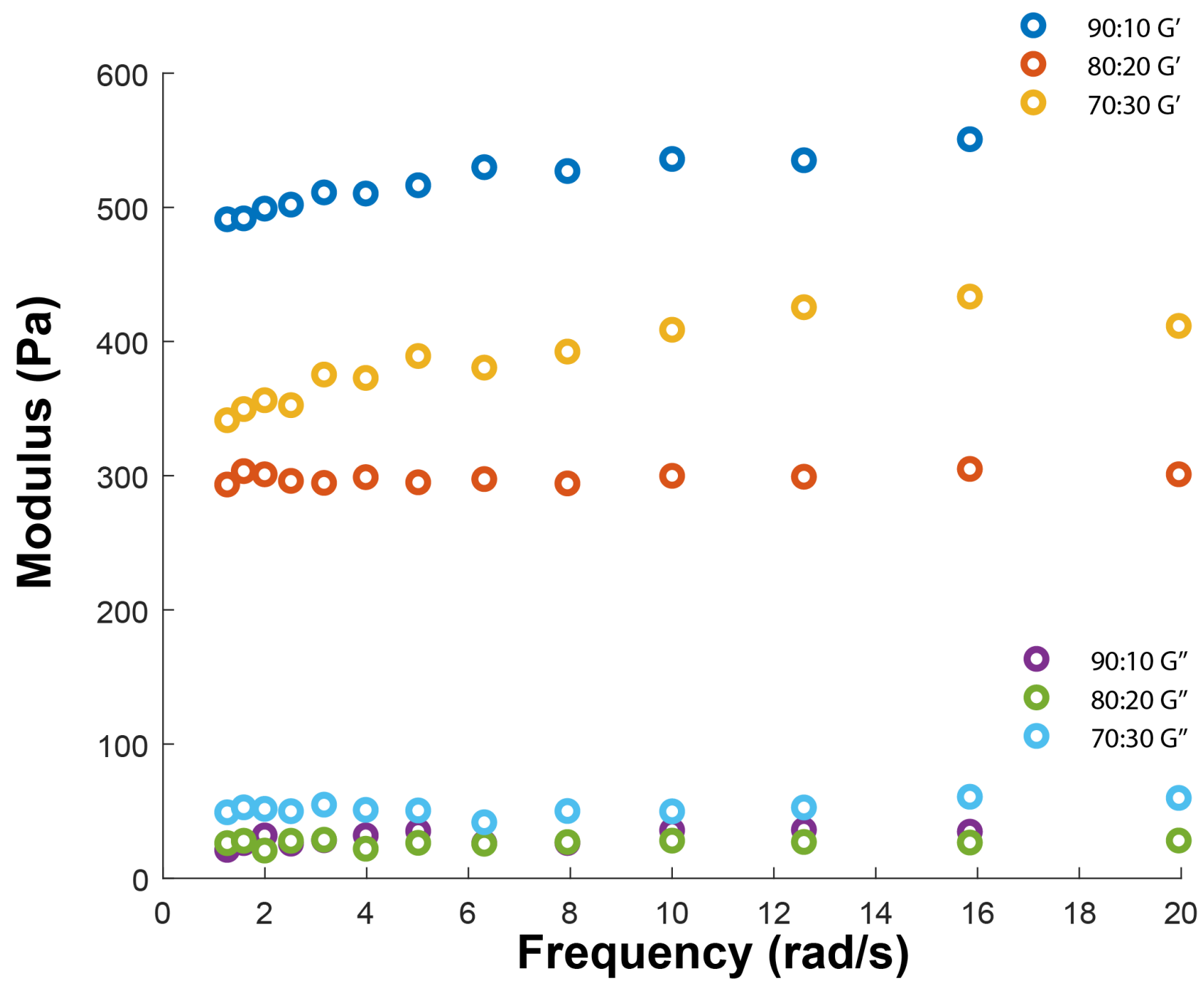

Figure S4: A frequency sweep of elastic modulus $\left(G^{\prime}\right)$ and viscous modulus $\left(G^{\prime \prime}\right)$ from 1 to 20 $\mathrm{rad} / \mathrm{s}$ shows that all of the heparin-containing formulations were able to form stable gels. The lack of frequency-dependence indicates predominantly covalent crosslinking. Importantly, the trends are consistent between all of the heparin-containing formulations, suggesting that differences in release rate and total release fraction were not due to differences in crosslinking. 